\title{
The effect of audio-visual education prior to coronary angiography on the state anxiety
}

\author{
Cengiz Basar ${ }^{*}$, Feyzullah Beşli ${ }^{1}$, Mesut Keçebaş ${ }^{2}$ Osman Kayapınar ${ }^{3}$ and Yasin Turker $^{3}$ \\ ${ }^{1}$ Department of Cardiology, Düzce State Hospital, Düzce, Turkey \\ ${ }^{2}$ Department of Cardiology, Düziçi State Hospital, Osmaniye, Turkey \\ ${ }^{3}$ Department of Cardiology, Düzce University Faculty of Medicine Hospital, Düzce, Turkey
}

\begin{abstract}
Objective: The purpose of this study is to evaluate the effectiveness of the audio-visual (video) education given to patients undergoing coronary angiography (CAG) over psychosocial (stress, anxiety) and physiological parameters.

Methods: This study included 120 consecutive patients (60 experiments, 60 controls) who underwent diagnostic CAG for the first time. Depression and anxiety levels were evaluated in all patients at admission. The day before the CAG procedure, the audio-visual (video) education was given to experimental group. The control group was informed only verbally about the procedure. 10-20 minutes prior to coronary angiography in all patients the level of state anxiety was measured, and blood pressure-heart rate were recorded. Data were statistically analyzed with SPSS16 statistical software.
\end{abstract}

Results: The average state anxiety score just before CAG procedure, the values of the pulse, systolic and diastolic blood pressure were significantly lower in the experimental group applied audio-visual education compared to control group given verbal information.

Conclusions: Compared to verbal information, the audio-visual(video) education for CAG applied to the patients before the procedure, could have a more positive effect on anxiety levels, blood pressures and heart rates.

\section{Introduction}

Coronary Artery Disease (CAD) is one of the most important causes of morbidity and mortality all over the world. Coronary angiography, widely used in the diagnosis and evaluation of CAD, is an invasive procedure. The methods used in the diagnosis and treatment of cardiovascular disease cause individuals to experience anxiety and fear of death $[1,2]$.

Anxiety and stress that occurs in patients result in increased blood pressure. Ongoing anxiety and stress may cause transient tachycardia, angina and myocardial ischemia [3]. Lack of knowledge about methods of diagnosis and treatment is one of the major causes of anxiety [4]. Studies showed the importance of stress and anxiety in coronary artery disease and the education given to patients reducing stress and anxiety significantly [5-7].

In this study, it was aimed to investigate the effect of the audiovisual(video) education over psychosocial (stress, anxiety) and physiological parameters in patients undergoing CAG.

\section{Material and methods}

We enrolled consecutive 120 patients (60experiments, 60 controls) who underwent coronary diagnostic angiography for the first time and without communication problems, psychiatric or mental illnesses who visited to the department of cardiology at our hospital, between $1^{\text {st }}$ September 2013 and $15^{\text {th }}$ March 2014. The indication for CAG was evaluation of chest pain. Informed consent was obtained from each subject for participation in this study. The study conforms with the principles outlined in the Declaration of Helsinki and was approved by the Ethics Committee for clinical research. A video that contains information about the applications prior to, during and after the CAG was prepared in accordance with literature data. The Video was shown one day before operation by 15 patients who underwent CAG and intelligibility, sound/image quality was evaluated $[8,9]$. At admission, experimental and control group patients were provided to answer all questions in the Beck depression scale, in the state-anxiety (STAI Form TX-1) and in the trait-anxiety(STAIFormTX-2) inventory. Questions were read one by one for illiterate patients andmarking was made in accordance with the verbal response. One day before CAG procedure, the audio-visual(video) education was applied to experimental group one by one. Patients in the control group were informed about the CAG procedure only verbally. After the education process, shortly before (10-20 minutes) CAG, the answers of all patients to the all questions in state-anxiety (STAI Form TX-1) inventory were recorded. Before CAG, the heart rate, systolic blood pressure (SBP), diastolic blood pressure (DBP) of the patients were measured. Patients using any drug which can alter blood pressure and heart rate were excluded.

\section{Beck depression inventory}

Beck depression scale was formed by combining the symptoms

Correspondence to: Cengiz Basar, MD, Department of Cardiology, Düzce Atatürk State Hospital, Düzce, Turkey, Tel: +90 380529 1300; E-mail: basarcengiz84@gmail.com

Key words: coronary angiography, audio-visual (video) education, state anxiety

Received: July 15, 2015; Accepted: August 24, 2015; Published: August 27, 2015 
often seen by depressed patients, depression specific attitudes observed in the clinical field and behaviors often seen [10]. Clinical observations systematically unified under 21 symptoms and attitudes were assessed between 0-3 according to the intensity. In the scale, the 21 questions measure cognition (11 questions), emotion (2), overt behavior (2), interpersonal problems (1) and somatic symptoms (5). The cut-off point for researches vary in scale but the cut-off point 17 is reported to be adequate to identify clinical depression.

\section{State-trait anxiety inventory}

State-Trait Anxiety Inventory was developed by Spielberger et al. (1970) in order to determine separately state and trait anxiety levels and stemmed from Two-Factor Theory of Anxiety of Spielberger [11]. State-Trait Anxiety Inventory is a self-assessment questionnaire which consists of short phrases and contains two separate scales consisting a total of forty items. State Anxiety scale refers an individual to describe how he felt at a given moment and in certain circumstances and to answer the feelings about the situation. Trait Anxiety Inventory refers an individual to describe how he felt usually across typical situations that everyone experiences on a daily basis. These two separate pages with twenty-point scale, are printed in the form of TX-1 and TX-2.

Statistical analysis was performed with the Statistical Package for Social Science for Windows (SPSS version 16). Group data of continuous variables are expressed as mean \pm standard deviation (mean $\pm \mathrm{SD}$ ). Categorical variables were given by the number and percentage (\%). To compare the groups according to the distribution of continuous variables, among the parametric tests in independent groups as $t$ test. Categorical variables were compared with Chi-square test. All probabilities were two-tailed and $p$ values less than 0.05 were regarded as statistically significant.

\section{Results}

In the study, $56.8 \%$ of individuals were males and $43.2 \%$ were females. The average age of the experimental group was $59.4 \pm 7$, the average age of the control group was $61.3 \pm 9.8(\mathrm{P}>0.05)$. Between two groups, according to marital status, educational level and having a family/nearby history of CAG there were no differences. It was discovered that all patients stated the need to be informed about CAG procedure (Table 1). Between the two groups, there were no significant difference between depression and anxiety scores before education $(\mathrm{P}>0.05)$ (Table 2). After education, compared to experimental group, heart rate, systolic and diastolic blood pressures before CAG were found significantly higher in control group $(\mathrm{P}=0.022, \mathrm{P}=0.01, \mathrm{P}<0.001$, respectively) (Table 3 ). The average state anxiety scores shortly before CAG procedure in the experimental group were significantly lower than the scores in the control group $(32.6 \pm 4.1,48.1 \pm 3.7 \mathrm{P}<0.001$, respectively) (Table 4 ).

\section{Discussion}

Coronary angiography in parallel with the increase in the incidence of coronary artery disease, is an invasive approach applied more frequently.

Studies have shown that people who will be underwent CAG procedure exposed to high anxiety due to facing life threatening disease, the process being performedthe heartas a vital organ, being curious how the results of process will come out, feeling the pain and insecure [12].

Anxiety, causing feelings of concern and the activation of the autonomic nervous system is a vague and undefinable state of fear. High anxiety level affects cardiovascular function and after a heart attack leads to the development of further complications. At the same time a high level of anxiety leads to compliance issues in the process of hospitalization and treatment. Anxiety can occur due to a physical disorder, as any attempt to apply to people is a cause of anxiety. The studies shows that anxiety delays healing in the body via biochemical changes, therefore providing information before the procedures promote healing by reducing anxiety [2].

In the literature, it has been noted that prior to invasive procedures patients with high levels of anxiety had high blood pressure during procedures, and in $53 \%$ of patients, anxiety related complications were seen. Problems and complications which patients had during invasive procedures due to pain and anxiety, can be minimized by the care plan in accordance with their requirements and a compatible teamwork $[13,14]$.

Anxiety has been shown to cause an increase in physiological parameters (heart rate and blood pressure) with an activationof autonomous system.In studies, it was observed that performing education before interventional procedures gave rise to a decrease in heart rate and blood pressure [5-7]. Also, in our study, the heart rate, systolic and diastolic blood pressure was found to be lower in the group of audio-visual (video) education than the control group.

In our study, while in both groups there was no significant

Table 1. The socio-demographic characteristics and of the disease-related information levels in both groups.

\begin{tabular}{|l|c|c|}
\hline & Experimental group n:60 & Control group n:60 \\
\hline Gender (Male/Female) & $33 / 27$ & $34 / 26$ \\
\hline Age (years) (mean \pm SD) & $59.4 \pm 7$ & $61.3 \pm 9.8$ \\
\hline $\begin{array}{l}\text { Marital status (n, \%) } \\
\text { Married }\end{array}$ & $50(83)$ & $48(80)$ \\
Single & $10(17)$ & $12(20)$ \\
\hline Need to be informed about coronary angiography procedure (n, \%) & $60(100)$ & 0.813 \\
\hline A family/near by history of coronary angiography (n, \%) & $30(50)$ & 0.812 \\
\hline Education level (middle school and above) (n, \%) & $18(30)$ & 0.996 \\
\hline
\end{tabular}

Table 2. Depression and anxiety scores comparison in both groups at admission.

\begin{tabular}{|l|c|c|c|}
\hline & Experimental group & Control group & P value \\
\hline Depression scores & $8.1 \pm 1.3$ & $8.5 \pm 2.7$ & 0.167 \\
\hline Trait anxiety scores & $6.3 \pm 1.3$ & $7.2 \pm 2.4$ & 0.268 \\
\hline State anxiety scores & $26.1 \pm 5.1$ & $28.1 \pm 4.7$ & $<0.001$ \\
\hline
\end{tabular}


Table 3. Physiological parameters comparison in both group shortly before coronary angiography procedure.

\begin{tabular}{|l|c|c|c|}
\hline & Experimental group & Control group & P value \\
\hline Heart rate (beat/min) & $82 \pm 11$ & $94 \pm 10$ & 0.022 \\
\hline Systolic blood pressure $(\mathrm{mm} \mathrm{Hg})$ & $124.2 \pm 12.8$ & $132.2 \pm 13.03$ & 0.013 \\
\hline Diastolic blood pressure $(\mathrm{mm} \mathrm{Hg})$ & $78.6 \pm 7.7$ & $86.4 \pm 4.8$ \\
\hline
\end{tabular}

Table 3. State Anxiety Score comparision in both groups, shortly before coronary angiography procedure.

\begin{tabular}{|l|c|c|c|}
\hline & Experimental group & Control group & $\boldsymbol{P}$ value \\
\hline State anxiety scores & $32.6 \pm 4.1$ & $48.1 \pm 3.7$ & $<0.001$ \\
\hline
\end{tabular}

difference in depression and anxiety levels before training, shortly before CAG in the audio-visual (video) group state anxiety was found to be significantly lower.

The previous studies have shown that the video education of patients who underwent coronary angiography was helpful in the reduction of stress and depression. In addition, studies demonstrated that method of sensory information was more effective than conventional methods in preparing the patients to procedures. It was showed that the video education given the patients before the coronary angiography reduces anxiety and stress effectively $[15,16]$. In the study of Stephenino et al the video education was found to increase the satisfaction and information of the patients [17]. In our study, the state anxiety which is indicative of instantaneous worry and stress, has been shown to be reduced by education given to patients. Therefore, in the preparation of patients to the coronary angiography, it sould be known that anxiety and stress of the patients may be effectively reduced by the assistant health personel via audio-visual (video) education other than medical preparation before the operation.

\section{Conclusion}

The audio-visual (video) education given before CAG procedures can have a positive effect on psychosocial and physiological parameters.

\section{References}

1. Buffum MD, Sasso C, Lanier E, Yelen M, Hayes A (2006) A music intervention to reduce anxiety before vascular angioraphy procedures. J Vasc Nurs 24: 68-73. [Crossref]

2. Corones K, Coyer FM, Theobald KA (2009) Exploring the information needs of patients who have undergone PCI. British Journal of Cardiac Nursing 4: 123-30.

3. Astley CM, Chew DP, Aylward PE, Molloy DA, De Pasquale CG (2008) A randomised study of three different informational AIDS prior to coronary angiography, measuring patient recall, satisfaction and anxiety. Heart Lung Circ 17: 25-32. [Crossref]

4. Karadeniz G, Altiparmak S, Aydemir O, Karadag F (2005) Anxiety and depression before coronary angiography. 3P Journal 13: 43-7.
5. Beasley M, Thompson T, Davidson J (2003) Resilience in response to life stress: The effects of coping style and cognitive hardiness. Personality and Individual Differences 34: 77-95.

6. Moradipanah F, Mohammadi E, Mohammadil AZ (2009) Effect of music on anxiety, stress, and depression levels in patients undergoing coronary angiography. East Mediterr Health J 15: 639-647. [Crossref]

7. Weeks BP, Nilsson U (2011) Music interventions in patients during coronary angiographic procedures: a randomized controlled study of the effect on patients' anxiety and well-being. Eur J Cardiovasc Nurs 10: 88-93. [Crossref]

8. Gallagher R, Trotter R, Donoghue J (2010) Preprocedural concerns and anxiety assessment in patients undergoing coronary angiography and percutaneous coronary interventions. Eur J Cardiovasc Nurs 9: 38-44. [Crossref]

9. Chair SY, Thompson DR (2005) Patient teaching prior to coronary angiography in Hong Kong: a pilot study. J Clin Nurs 14: 114-115. [Crossref]

10. Beck AT, Ward CH,Mendelson M, Mock J, Erbaugh J (1961) An inventory for measuring depression. Arch Gen Psychiatry 4: 561-71.

11. Spielberger CD, Gorsuch RL, Lusahene RE (1970) Manual for State-Trait Anxiety Inventory. California, Consulting Psychologists Press. 1970

12. Nilsson U (2012) Effectiveness of music interventions for women with high anxiety during coronary angiographic procedures: a randomized controlled. Eur J Cardiovasc Nurs 11: 150-153. [Crossref]

13. Köllner V, Bernardy K (2006) How to reduce stress and anxiety in patients undergoing cardiac catheterization? Clin Res Cardiol 95: 511-513. [Crossref]

14. Philippe F, Meney M, Larrazet F, Ben Abderrazak F, Dibie A, et al. (2006) Effects of video information in patients undergoing coronary angiography. Arch Mal Coeur Vaiss 99: 95-101. [Crossref]

15. Jamshidi N, Abbaszadeh, A, Kalyani MN (2009) Effects of video information on anxiety, stress and depression of patients undergoing coronary angiography. PakJ Med Sci 25: 901-6.

16. Balci A, Enç N (2013) The effect of audio-visual education given to coronary angiography patients over physiological and psychosocial parameters. Turkish Journal of Cardiovascular Nursing 4: 41-50.

17. Steffenino G, Viada E, Marengo B, Canale R; Nursing and the Medical Staff of the Cardiac Catheterization Unit (2007) Effectiveness of video-based patient information before percutaneous cardiac interventions. J Cardiovasc Med (Hagerstown) 8: 348353. [Crossref]

Copyright: (C2015 Basar C. This is an open-access article distributed under the terms of the Creative Commons Attribution License, which permits unrestricted use, distribution, and reproduction in any medium, provided the original author and source are credited. 